\title{
Release of sea-floor maps
}

\section{Washington}

THE US Navy made a U-turn last week and announced that it will permit the release of most of the detailed sea-floor maps of the US Exclusive Economic Zone (EEZ) prepared by the National Oceanic and Atmospheric Administration (NOAA). The announcement follows rumours that the Navy was steaming in the other direction and was about to condemn all high-resolution bathymetric data collected in federal programmes to the same fate as the NOAA data, classified by a White House memo from Vice Admiral John Poindexter in 1985.

The change in policy comes as a welcome relief to oceanographers who were living "under threat that our data might become classified and that we would not be able to freely distribute our results" according to Ken Macdonald of the Marine Science Institute at the University of California at Santa Barbara. The NOAA maps are likely to be an exciting data source, he said, providing detailed information on many scientifically interesting areas off the west coast.

Restrictions on the NOAA maps will not be lifted for all of the 130,000 square kilometres of sea bed they cover. Excluded will be areas, of yet undefined size, around ballistic missile submarine's home ports. The Navy's own massive collection of high-resolution bathymetric data will definitely remain classified. Most of it is believed to be for the deep oceans (the location of surveyed areas is also classi-

fied) and would be of enormous value to oceanographers. But the Navy argues that it needs the data kept secret as it uses it to determine the best sites for sensors to detect enemy submarines and to map the gravity anomalies which affect the flight of ballistic missiles. Occasional glimpses of part of the Navy data have been given on a "need to know" basis, producing, for example, the map of the North Atlantic sea mounts published by David Epp and Christian Smoot (see Nature 337, 254; 1989). But even in this case the location of the sea mounts was not given with full accuracy.

The Navy's tough policy on bathymetric data has done little good to US industry. General Instrument Corporation, the major US maker of multibeam sonar, has had to refuse several export orders, while Finnish, German and Norwegian companies have sailed away with business. The damage to US industry, plus the knowledge that it was becoming possible to buy foreign sonars that would map the sea floor as accurately and faster than NOAA's equipment, may have helped to prod the Navy into a more open attitude.

Most oceanographers attribute the change in policy to last year's appointment of Rear Admiral Richard Pittenger as Oceanographer of the Navy. Despite his background in anti-submarine warfare, he is believed to value academic research. But the Navy keeps quiet about its policy decisions and will not give reasons for its change in course.

Alun Anderson RADIOTELESCOPE

\section{Green Bank failure identified}

\section{Washington}

THE cause of the sudden collapse of the 300-foot radiotelescope at Green Bank, West Virginia, last November (see Nature 296, 336; 1988), on a night without wind, rain or snow, has been traced to the fracture of a single, highly stressed steel connection plate, according to an independent inquiry which submitted its findings to the National Science Foundation last week.

That conclusion leaves the National Radio Astronomy Observatory free to clear away the enormous tangle of steel that had been left undisturbed while the inquiry was in progress. But it makes it no easier to sort out the scientific and political issues surrounding the question of whether the telescope should be rebuilt.

The three-man inquiry panel found no evidence of inadequate maintenance of the connection plate, or of improper operation of the telescope. But modern computer structural stress analyses, show that stresses in many parts of the telescope "were substantially higher that is permissible today".

The telecope's design problems can be overcome using modern techniques, says the report, and provide no technical obstacles to its replacement. West Virginia's two Democrat Senators, Robert C. Byrd and John D. Rockefeller, are already demanding that a similar, state-ofthe-art telescope be built as the "best promise for jobs, education, tourism and scientific prestige" in a state with little else to offer in the way of large. basic research facilities. Byrd, who holds a powerful position in the Senate Appropriations Committee, says he "will aggressively pursue funding" for the telescope. Plans for a supplemental appropriation to the NSF budget for a new telescope are already under way.

But astronomers are not necessarily sure that replacing Green Bank would be the best use of the $\$ 75$ million required. The large telescope was valuable for survey and mapping and was able to detect

\section{Protest as Pasteur speaks English}

\section{Paris}

A DECISION to give the Pasteur Institute's journal an English title has caused confusion and protest in the French press, but seems to have left the scientific community unscathed. Under the banner "Goodbye Pasteur!", the French national newspaper, Le Monde, broke the news that, in future, the Annales de l'Institut Pasteur will be published only in English, for the first time since it was created in 1887 . This, ran the article, sounds the death-knell for Frenchlanguage science.

Two changes have been made to the journal. The title will now be Research in ... (immunology, virology or microbiology, according to the discipline covered). Second, the review panel has been widened to include non-Pastorians and foreign scientists. But, says the Pasteur Institute, articles submitted in French and accepted for publication will be printed in French, while articles in English will continue to have a French abstract. For the press, the changes signal the disappearance of a flagship of French science under the 'tyranny' of the English language. But the Pasteur Institute sees things differently. "In 1973 only 10 to 15 per cent of the articles we received were in English, but in 1987 the proportion was almost 100 per cent", says a spokeswoman. "But of the articles we published, 58 per cent were from Frenchspeaking authors and over 80 per cent of these were originally written in English. The title of the review, however, suggested that it was not open to the scientific community as a whole and so researchers started to send their papers elsewhere. The Annales de l'Institut Pasteur has to survive." Peter Coles

faint sources, including a pulsar in the Crab nebula. But according to Kurt Riegel of NSF's Division of Astronomy, a decision to rebuild the telescope would face competition from projects to upgrade the radiotelescope at Arecibo, to build large optical telescopes and to enhance the image-processing capabilities of the National Radio Astronomy Observatory's very large arrays.

If a new radiotelescope is not built, "it does not bode well for the site at Green Bank", according to the facility's director, Paul A. Vanden Bout. A 140-foot radiotelescope remains at Green Bank but it is 26 years old. A possible solution, already suggested by NSF officials, is to build the eastern end of the proposed Laser Interferometer Gravitational Wave Observatory (LIGO) at Green Bank. The project requires a facility in California and in the east to be run in coincidence. But Byrd and Rockefeller say that while they welcome LIGO, they want the radiotelescope replaced too.

Alun Anderson 